\title{
ANALISIS POSTUR KERJA MENGGUNAKAN METODE RAPID UPPER LIMB ASSESSMENT (RULA) DI UMKM KERUPUK KEMPLANG 32 KECAMATAN BUMI WARAS BANDAR LAMPUNG
}

\author{
Riska Restiyani $^{1}$, Susanti Sundari ${ }^{*}$ \\ Progam Studi Teknik Industri Fakultas Teknik \\ Universitas Tulang Bawang Lampung \\ Jl. Gajah Mada No. 34 Kotabaru Bandar Lampung \\ *Penulis Korespondensi: susanti.sundari@utb.ac.id
}

\begin{abstract}
This study discusses work posture analysis using the Rapid Upper Limb Assessment (RULA) method at UMKM Kerupuk Kemplang 32, Bumi Waras District, Bandar Lampung. The purpose of this study was to determine unsafe work postures for workers, and to minimize injuries to the skeletal system and nervous system caused by repetitive movements (Cumulative Trauma Disorders), how the influence of work attitudes or postures of workers and the workplace, provide recommendations for appropriate work postures safe based on the Rapid Upper Limb Assessment (RULA) method. This research is a descriptive study with data analysis using the RULA method. The data collection method uses primary data in the form of worker posture data which includes upper arms, forearms, wrists, hands, neck, back and legs. The results of this study indicate that the working posture of making kemplang cracker dough is divided into two activities, namely taking sago water and making the dough, both of which have a score of 7 which indicates Action Level 4 and the roasting section of kemplang crackers has the same score, 7 indicating Action Level 4. From these data, it can be concluded that this work posture needs to be improved in the near future.
\end{abstract}

Keyword: Cumulative Trauma Disorders, RULA, UMKM, Work Posture

\section{Pendahuluan}

Usaha Mikro Kecil Menengah (UMKM) merupakan pemain utama dalam kegiatan ekonomi di Indonesia. UMKM dapat memperluas lapangan kerja dan memberikan pelayanan ekonomi secara luas kepada masyarakat dan dapat berperan dalam meningkatkan perekonomian masyarakat, mengurangi pengangguran dan meningkatkan kesejahteraan masyarakat. Salah satu UMKM yang ada di
Provinsi Lampung yaitu usaha kerupuk kemplang yang dalam memproduksinya melibatkan masyarakat sekitar, artinya masyarakat dapat berdaya melalui aktivitas UMKM kerupuk kemplang yang ada.

Kerupuk kemplang merupakan makanan ringan yang digemari masyarakat karena rasanya yang gurih dan renyah. Makanan ini dibuat dari adonan tepung tapioka dan dicampur dengan bahan perasa seperti udang atau ikan. Kerupuk kemplang 
dibuat dengan sistem mengukus adonan sebelum dipotong tipis-tipis, dikeringkan di bawah sinar matahari kemudian di panggang dengan bara api. Ditengah usaha kerupuk kemplang yang semakin berkembang penggunaan tenaga manusia dalam dunia industri masih dominan, terutama kegiatan penanganan material secara manual (Manual Material Handling). Permasalahan yang ditemui di tempat kerja pada umumnya adalah faktor kelelahan kerja contohnya pada salah satu

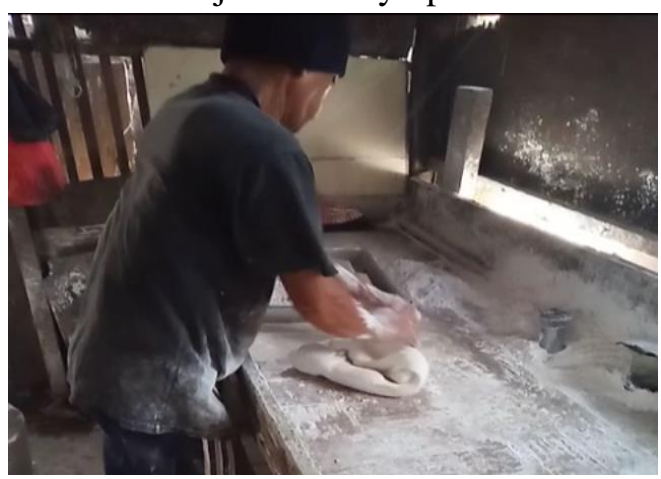

Gambar 1. Postur Kerja Pada Proses Pengulenan Adonan

Sumber: Data Primer

Postur kerja merupakan pengaturan sikap tubuh saat bekerja. Sikap kerja yang berbeda akan menghasilkan kekuatan yang berbeda pula. Kenyamanan tercipta bila pekerja telah melakukan postur kerja yang baik dan aman. Aktifitas manual material handling berisiko besar sebagai penyebab utama penyakit tulang belakang (Low Back Pain). Beban kerja yang berat, postur kerja yang salah dan perulangan gerakan yang tinggi serta adanya getaran terhadap keseluruhan tubuh merupakan keadaan yang memperburuk penyakit tersebut (Kasjono 2017). Keluhan muskuloskeletal atau gangguan otot rangka merupakan kerusakan pada otot, saraf, tendon, ligament, persendian, kartilago. proses pengulenan adonan kerupuk kemplang, jika dilakukan secara berulang (repetitive), posisi kerja berdiri yang cukup lama akan memberikan tekanan pada syaraf, pembuluh darah dan otot pada kaki sehinggga dapat menimbulkan keluhan muskuloskeletal. Berikut adalah contoh gambar 1, pekerja bagian pengulenan adonan kerupuk kemplang.

Kerusakan pada otot dapat berupa ketegangan otot, inflamasi, dan degenerasi. Sedangkan kerusakan pada tulang dapat berupa memar, mikro faktor, patah, atau terpelintir (Umyati 2018).

Pada umumnya pekerja menganggap keluhan itu hal yang biasa karena lelah setelah bekerja, dengan posisi berdiri dan membungkuk dalam waktu yang lama dan seluruh pekerjaan dilakukan secara fisik (manual). Dengan pola kerja manual seperti ini banyak ditemui keadaan yang tidak sesuai dengan prinsip ergonomi jika landasan kerja terlalu tinggi maka pekerja akan mengangkat bahu untuk menyesuaikan dengan ketinggian landasan kerja, sehingga menyebabkan sakit pada bahu dan leher, sebaliknya bila landasan terlalu rendah maka tulang belakang akan membungkuk sehingga menyebabkan kenyerian pada bagian belakang (backache) (Setiawan, A. 2017).

Di UMKM Kerupuk Kemplang 32 dimana survey awal ditemukan banyak aktifitas yang menggunakan otot-otot sendi, dimana beberapa pekerja mengeluhkan sakit-sakit pada bagian punggung, tulang belakang, leher dan pinggang diakibatkan posisi kerja yang 
terus menerus menerima beban-beban statis dan dalam jangka waktu lama. Proses yang umum dilakukan dalam pembuatan kerupuk kemplang adalah pengulenan, pencetakan adonan, pengukusan adonan, pengeringana adonan, pemanggangan, dan pengemasan. Berdasarkan hasil dari banyak penelitian yang pernah ada, pada umumnya keluhan pada sistem musculoskeletal diakibatkan penggunaan postur kerja yang tidak baik. Tujuan penelitian adalah mengidentifikasi dan mengevaluasi postur kerja yang tidak aman bagi pekerja di UMKM pembuatan kerupuk kemplang, mengetahui bagaimana pengaruh antara sikap atau postur kerja pekerja dengan tempat kerja, dan memberikan rekomendasi postur kerja yang aman berdasarkan metode RULA.

\section{Ergonomi}

Menurut Pusat Departemen

Kesehatan Kerja Departemen Kesehatan Republik Indonesia, pengertian Ergonomi adalah ilmu yang mempelajari perilaku manusia dalam kaitannya dengan pekerjaan mereka. Faktor yang tidak ergonomi dapat menimbulkan masalah terhadap pekerja dan menyebabkan gangguan baik secara fisik maupun secara psikologis. Upayanya antara lain berupa menyesuaikan ukuran tempat kerja dengan dimensi tubuh agar tidak melelahkan.

\section{Postur dan Gerakan Kerja}

Postur kerja merupakan titik penentu dalam menganalisa keefektifan dari suatu pekerjaan. Apabila postur kerja yang dilakukan oleh operator sudah baik dan ergonomis maka dapat dipastikan hasil yang diperoleh oleh operator tersebut akan baik. Apabila operator mudah mengalami kelelahan maka hasil pekerjaan yang dilakukan operator tersebut juga akan mengalami penurunan dan tidak sesuai dengan yang diharapkan (Susihono, 2012).

Beberapa jenis pekerjaan akan memerlukan postur kerja tertentu yang terkadang tidak menyenangkan, kondisi kerja seperti ini memaksa pekerja selalu berada pada postur kerja yang tidak alami dan berlangsung dalam jangka waktu yang lama, hal ini akan mengakibatkan pekerja cepat lelah, adanya keluhan sakit pada bagian tubuh, cacat produk bahkan cacat tubuh. Pada saat bekerja sebaiknya postur dilakuakan secara alamiah sehingga dapat meminimalisasi timbulnya cidera musculoskeletal. Pergerakan yang dilakukan saat bekerja meliputi flexion, extension, abduction, adducton, rotation, pronation dan supination.

Flexion adalah gerakan dimana
sudut antara dua tulang terjadi pengurangan. Extension adalah gerakan merentangkan (stretching) dimana terjadi peningkatan sudut antara dua tulang. Untuk lebih jelasnya dapat dilihat pada gambar 2.berikut.

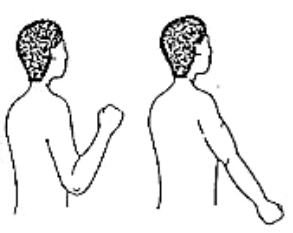

(a)

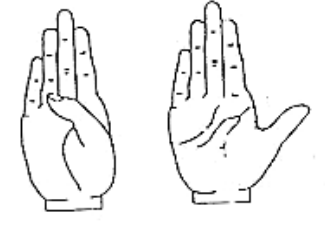

(b)

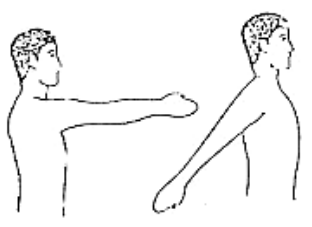

Gambar 2. Pergerakan Flexion Dan Extension Pada (A) Bahu, (B) Telapak Tangan Dan (C) Lengan.

Sumber: Lynn Mcatamney \& Nigel Corlet, 1993 dalam Siswanto, 2019 
Abduction adalah pergerakan menyamping menjauhi dari sumbu tengah (the median plane) tubuh. Adduction merupakan pergerakan kearah sumbu tengah (the median palne) tubuh. Penjelasannya mengenai ini dapat dilihat pada gambar 3 dibawah ini:

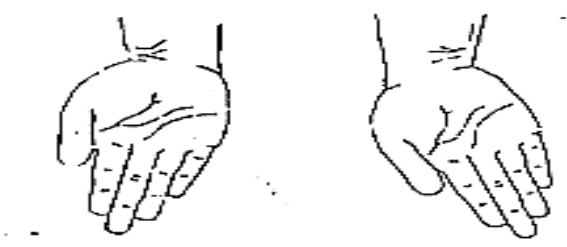

(a)

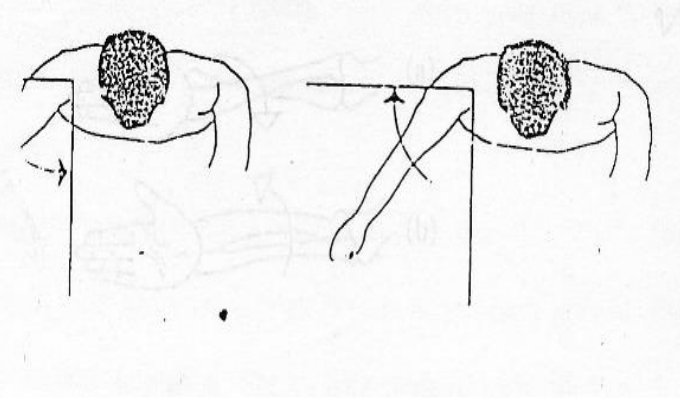

(b)

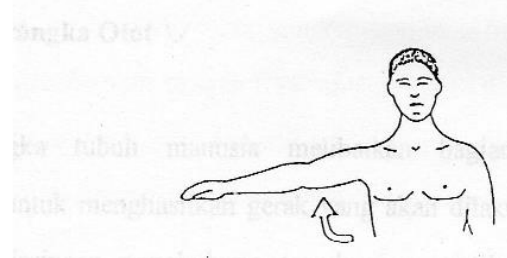

(c)

Gambar 3. Pergerakan Abduction Dan Adduction Pada (A) Telapak Tangan, (B) Bahu Dan (C) Abduction Vertical Sumber: Lynn Mcatamney \& Nigel Corlet, 1993 dalam Siswanto, 2019

Rotation adalah pergerakan dimana terjadi perputaran pada tulang. Penjelasannya dapat dilihat pada gambar 4.

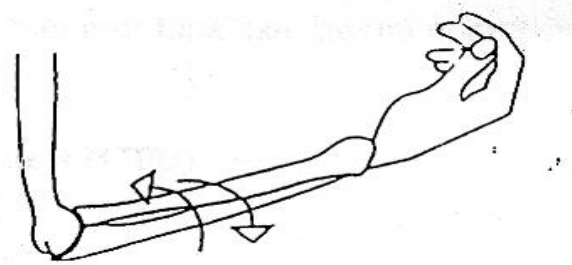

Gambar 4. Pergerakan Rotation Sumber: Lynn Mcatamney \& Nigel Corlet, 1993 dalam Siswanto, 2019

Pronation adalah perputaran bagian tengah (menuju kedalam) dari anggota tubuh. Supination adalah perputaran kerarah samping (menuju keluar) dari anggota tubuh. Penjelasannya dapat dilihat pada gambar 5 dibawah ini:

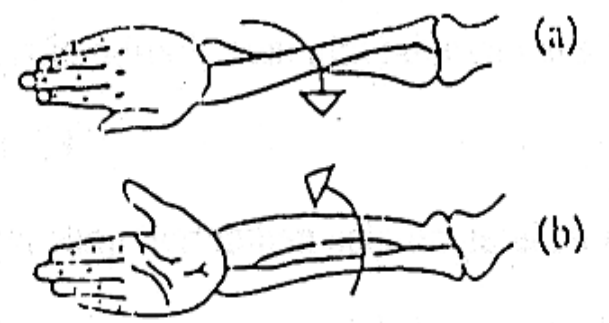

Gambar 5. Pergerakan Pada Posisi Pada Lengan (A) Supination Dan (B)

Pronation

Sumber: Lynn Mcatamney \& Nigel Corlet, 1993 dalam Siswanto, 2019

\section{Kerja Otot Statis Dan Dinamis}

Otot adalah organ yang terpenting dalam sistem gerak tubuh, otot dapat bekerja secara statis (postural) atau dinamis (rhythmic). Kerja otot statis adalah kerja otot yang tidak bergerak atau dengan kata lain otot hanya diam sedangkan pada kerja otot dinamis kontraksi dan relaksasi terjadi silih berganti. Pekerjaan statis menyebabkan kehilangan energi yang tidak perlu. Kelelahan dan keluhan pekerja pada 
muskuloskeletal merupakan salah satu indikasi adanya gangguan kesehatan dan keselamatan pekerja. Kelelahan otot merupakan suatu penurunan kapasitas otot dalam bekerja akibat konstraksi tulang. Otot yang lelah akan menunjukkan kurangnya kekuatan, bertambahnya waktu kontraksi dan relaksasi, berkurangnya koordinasi serta otot menjadi gemetar (Tarwaka, 2014).

\section{Cumulative Trauma Disorders (CTD)}

Cumulative Trauma Disorders adalah cidera pada sistem kerangka dan sistem syaraf yang disebabkan karena pergerakan berulang, penggunaan tenaga berlebihan, vibrasi, tekanan mekanis (tekanan terhadap permukaan keras), posisi menopang atau menahan. Cumulative Trauma Disorders juga dapat ditimbulkan dari tenaga kerja yang melakukan pekerjaan dengan posisi postur tubuh dan pergelangan tangan yang kurang baik serta harus melakukan pekerjaan yang berulang-ulang pada hanya satu jenis otot (Hastuti, 2009). Sikap tubuh yang dipaksakan adalah salah satu penyebab umum CTD.

\section{Rapid Upper Limb Assesment (RULA)} Rapid Upper Limb Assessment (RULA) merupakan suatu metode penelitian untuk menginvestigasi gangguan pada anggota badan bagian atas. Metode ini dirancang oleh Lynn Mc Atamney dan Nigel Corlett pada tahun 1993 yang menyediakan sebuah perhitungan tingkatan beban muskuluskeletal di dalam sebuah pekerjaan yang memiliki resiko pada bagian tubuh dari perut hingga leher atau anggota badan bagian atas. Metode ini tidak membutuhkan peralatan special dalam penetapan penilaian postur leher, punggung, dan lengan atas. Setiap pergerakan diberi skor yang telah ditetapkan.

\section{Metode Penelitian}

\section{Teknik Pengumpulan Data}

A. Data Primer, data yang diperoleh langsung dari sumber-sumber yang diamati dan dicatat pertama kali,data yang diambil diantaranya:

a. Postur pekerja yang meliputi lengan atas, lengan bawah, pergelangan

b. Tangan, leher, punggung dan kaki.

B. Data sekunder, data yang diperoleh dari luar perusahaan meliputi studi pustaka dan disiplin keilmuan yang mendukung serta mempunyai hubungan dengan kasus yang diteliti.

\section{Metode dan Jenis Penelitian}

Metode yang digunakan dalam penelitian ini adalah metode RULA (Rapid Upper Limb Assesment). Jenis penelitian ini merupakan penelitian deskriptif yang bertujuan untuk memperoleh gambaran penelitian.

\section{Teknik Pengolahan Data}

Tahap Pengolahan Data

Pengembangan metode untuk

pencatatan postur kerja untuk menghasilkan suatu metode yang cepat digunakan, tubuh dibagi menjadi dua bagian, yaitu grup Adan grup B. Grup A meliputi lengan atas dan lengan bawah serta pergelangan tangan. Sementara grup B meliputi leher, badan dan kaki.

Perkembangan sistem untuk pengelompokan skor postur bagian tubuh dengan cara menentukan skor untuk masing-masing postur A dan B. Kemudian 
skor tersebut dimasukkan dalam tabel A untuk memperoleh skor A.

Pengembangan Grand Score dan Daftar Tindakan Penentuan Grand Score untuk memperoleh nilai action level dan tindakan yang harus dilakukan.

\section{Analisis Data}

Penilaian postur kerja diperlukan ketika didapati bahwa postur kerja pekerja memiliki resiko menimbulkan cedera muskuleskeletal yang diketahui secara visual atau melalui keluhan dari pekerja itu sendiri. Dengan adanya penilaian dan analisis perbaikan postur kerja, diharapkan dapat diterapkan untuk mengurangi atau menghilangkan resiko cedera muskuluskeletal yang dialami pekerja.

\section{Hasil Dan Pembahasan}

Fase Gerakan Karyawan 1 Kegiatan Pembuatan Adonan

Kegiatan Pembuatan adonan terbagi menjadi dua postur kerja yaitu:

\section{a. Postur Kegiatan Pengambilan Air Sagu}

Postur kerja pertama adalah saat pengambilan air sagu. Kegiatan tersebut dapat dilihat pada gambar 6 berikut:

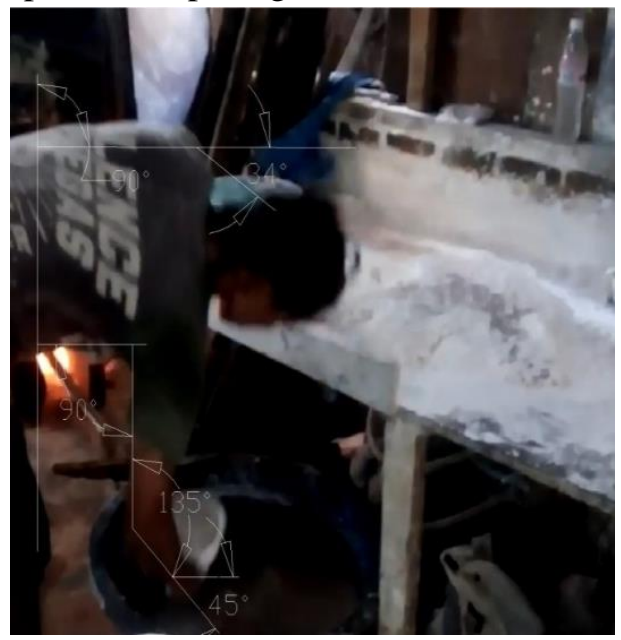

Gambar 6. Postur Kerja Pengambilan Air Sagu

\section{Sumber: Data Primer}

\section{$\underline{\text { Grup A }}$}

1. Postur tubuh bagian lengan atas (upper arm) Lengan atas membentuk sudut $90^{\circ}$ diberi skor : 4

2. Postur tubuh bagian lengan bawah (lower arm) Lengan bawah membentuk sudut $>100^{\circ}$ skor :2

3. Postur tubuh bagian pergelangan tangan (wrist) Sudut pergelangan tangan $15^{0+}$ diberi skor : 3

4. Putaran pergelangan tangan (wrist twist) berada di dekat dengan putaran di beri skor : 2

\section{b. Postur Kegiatan Pembentukan Adonan}

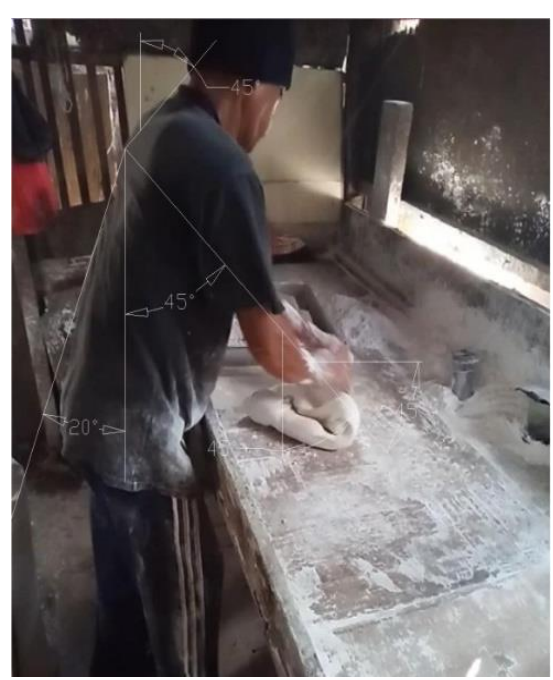

Gambar 7. Postur Kerja Saat

Membentuk Adonan

Sumber: Data Primer

\section{$\underline{\text { Grup A }}$}

1. Postur tubuh bagian lengan atas (upper arm) Lengan atas membentuk sudut $45^{\circ}$ diberi skor : 3 
2. Postur tubuh bagian lengan bawah (lower arm) Lengan bawah membentuk sudut $60^{\circ}-100^{\circ}$ skor : 1

3. Postur tubuh bagian pergelangan tangan (wrist) Sudut pergelangan tangan $15^{0+}$ diberi skor :3

4. Putaran pergelangan tangan (wrist twist) berada di dekat dengan putaran di beri skor : 2

\section{Fase Gerakan Karyawan 2 Pemanggangan Kerupuk Kemplang}

Hasil kode RULA dari postur kerja pada gambar 8 dijelaskan, sebagai berikut:

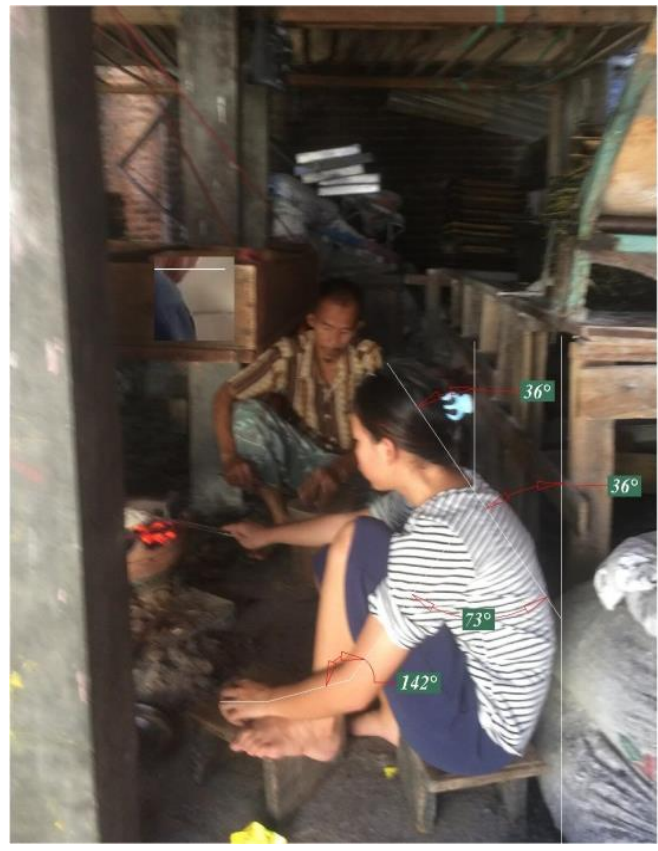

Gambar 8. Postur Kerja

Pemanggangan Kerupuk Kemplang Sumber: Data Primer

\section{Grup A}

1. Postur tubuh bagian lengan atas (upper arm) Lengan atas membentuk sudut $73^{\circ}$ diberi skor : 3
2. Postur tubuh bagian lengan bawah (lower arm) Lengan bawah membentuk sudut $60^{\circ}>100^{\circ}$ skor : 2

3. Postur tubuh bagian pergelangan tangan (wrist) Sudut pergelangan tangan $0^{0-} 15^{0+}$ diberi skor :2

4. Putaran pergelangan tangan (wrist twist) berada di dekat dengan putaran di beri skor : 1

a. Skor postur tubuh grup A pada kegiatan pemanggangan Kerupuk Kemplang berdasarkan table 1 adalah : 4

b. Skor aktifitas pemanggangan yang dilakukan berulang-ulang lebih dari 4 kali permenit dengan skor : 1

c. Skor Beban yang diterima sesekali atau tenaga kurang dari $2 \mathrm{~kg}$ mendapatkan skor : 0

Total skor yang didapat pada grup A aktifitas pemanggangan Kerupuk Kemplang 32 adalah $4+1+0=5$

\section{Grup B}

1. Postur tubuh bagian leher (neck) Leher membentuk sudut $20^{\circ}+$ diberi skor : 3

2. Postur tubuh bagian batang tubuh (trunk) Batang tubuh membentuk sudut $20^{0}-60^{0}$ diberi skor : 3

3. Postur tubuh bagian kaki (legs) Kaki tidak seimbang dengan skor : 2

Hasil penentuan skor untuk grup B

\section{Pembahasan}

Berdasarkan analisis dan pengolahan data didapat rekapitulasi hasil perhitungan pekerja UMKM Kerupuk Kemplang 32 dapat dilihat pada tabel-tabel berikut: 
Tabel 1. Rekapitulasi Hasil Perhitungan Postur Kerja

\begin{tabular}{ccccc}
\hline No & Kegiatan & $\begin{array}{c}\text { Skor } \\
\text { Akhir }\end{array}$ & $\begin{array}{c}\text { Level } \\
\text { Action }\end{array}$ & Tindakan Perbaikan \\
\hline 1. & Pengambilan Air Sagu & 7 & 4 & Tempat Kerja \\
2. & $\begin{array}{c}\text { Pembuatan adonan } \\
\text { Kerupuk Kemplang }\end{array}$ & 7 & 4 & Tempat Kerja \\
3. & Pemanggangan & 7 & 4 & Tempat Kerja \\
\hline
\end{tabular}

Dapat diketahui adanya action level yang merekomendasikan perubahanperubahan dan perbaikan. Dalam hal ini yang dimaksud ada dua macam perabikan yaitu perbaikan pada postur tubuh saat bekerja dan perbaikan aktivitas kerja dengan merancang serta mengimplementasikan alat bantu.
Perbaikan dengan alat bantu tersebut akan mempengaruhi perbaikan postur kerja.

a. Perbaikan metode kerja pada aktivitas Pembuatan Adonan Kerupuk Kemplang 32 dapat dilihat pada tabel 2 dan 3 berikut:

Tabel 2. Perbaikan Metode Kerja Pengambilan Bahan Baku Sagu Cair

\begin{tabular}{cll} 
No & \multicolumn{1}{c}{ Metode Awal } & \multicolumn{1}{c}{ Metode Perbaikan } \\
\hline 1 & $\begin{array}{l}\text { Pengambilan sagu cair dilakukan } \\
\text { dengan cara punggung } \\
\text { membungkuk, dikarenakan letak } \\
\text { sagu cair berada di lantai tanpa } \\
\text { adanya landasan }\end{array}$ & $\begin{array}{l}\text { Menggunakan landasan seperti meja atau } \\
\text { yang lainnya diharapkan pungggung atau } \\
\text { badan pekerja tidak membungkuk (bak } \\
\text { sagu cair di letakkan diatas meja) }\end{array}$ \\
\hline
\end{tabular}

Tabel 3. Perbaikan Metode Kerja Pembuatan Adonan Kerupuk Kemplang

\begin{tabular}{clll}
\hline No & \multicolumn{2}{c}{ Metode Awal } & \multicolumn{2}{c}{ Metode Perbaikan } \\
\hline 1 & $\begin{array}{l}\text { Pembentukan adonan kerupuk } \\
\text { kemplang menggunakan meja yang } \\
\text { terlalu rendah sehingga punggung dan } \\
\text { pundak terlalu membungkuk }\end{array}$ & $\begin{array}{l}\text { Menggunakan meja landasan yang } \\
\text { tidak terlalu rendah diharapkan } \\
\text { punggung dan pundak pekerja tidak } \\
\text { membungkuk }\end{array}$ \\
\hline
\end{tabular}


Tabel 4. Analisis Perbaikan Postur Kerja Pembuatan Adonan Kerupuk Kemplang

\begin{tabular}{|c|c|c|c|c|c|}
\hline Postur & Kegiatan & $\begin{array}{l}\text { Action } \\
\text { Level }\end{array}$ & Kondisi Awal & Keterangan & Rekomendasi \\
\hline 1 & $\begin{array}{l}\text { Pengambilan } \\
\text { bahan baku sagu } \\
\text { cair }\end{array}$ & 4 & $\begin{array}{lr}\text { Punggung } & \\
\text { membungkuk } & 90^{0} \\
\text { pergerakan } & \text { lengan } \\
\text { menjauhi } & \text { posisi } \\
\text { alamiah } & \end{array}$ & $\begin{array}{l}\text { Punggung } \\
\text { membungkuk } \\
\text { menyebabkan nyeri } \\
\text { otot pada leher, bahu, } \\
\text { punggung dan } \\
\text { pingggang }\end{array}$ & $\begin{array}{l}\text { Punggung tidak } \\
\text { terlalu membungkuk }\end{array}$ \\
\hline 2 & $\begin{array}{l}\text { Pembentukan } \\
\text { adonan Kerupuk } \\
\text { Kemplang }\end{array}$ & 4 & $\begin{array}{l}\text { Punggung } \\
\text { membungkuk } 20^{0}, \\
\text { bahu terangkat keatas }\end{array}$ & $\begin{array}{l}\text { Punggung } \\
\text { membungkuk } \\
\text { menyebabkan nyeri } \\
\text { otot pada leher, bahu, } \\
\text { dan punggung, }\end{array}$ & $\begin{array}{l}\text { Punggung tidak } \\
\text { terlalu membungkuk } \\
\text { dan pundak tidak } \\
\text { terlalu terangkat } \\
\text { keatas }\end{array}$ \\
\hline
\end{tabular}

b. Perbaikan Metode Kerja pada Aktifitas Pemanggangan Kerupuk Kemplang 32 dapat dilihat pada tabel 5 berikut:

Tabel 5. Perbaikan Metode Kerja Pemanggangan Kerupuk Kemplang

\begin{tabular}{|c|c|c|}
\hline No & Metode Awal & Metode Perbaikan \\
\hline 1 & $\begin{array}{l}\text { Pekerja harus menekukkan } \\
\text { kakinya saat melakukan } \\
\text { pemanggangan kerupuk } \\
\text { kemplang }\end{array}$ & $\begin{array}{l}\text { Untuk mencegah agar kaki tidak } \\
\text { terlalu di tekuk kedalam sebaiknya } \\
\text { menggunakan kursi yang tidak } \\
\text { terlalu pendek }\end{array}$ \\
\hline
\end{tabular}

Tabel 6. Analisis Perbaikan Postur Kerja Pemanggangan Kerupuk Kemplang

\begin{tabular}{|c|c|c|c|c|c|c|}
\hline $\begin{array}{l}\text { Post } \\
\text { ur }\end{array}$ & Kegiatan & $\begin{array}{l}\text { Action } \\
\text { Level }\end{array}$ & $\begin{array}{l}\text { Kondisi } \\
\text { Awal }\end{array}$ & Keterangan & Rekomendasi & Keterangan \\
\hline 1 & $\begin{array}{l}\text { Pemangg } \\
\text { angan } \\
\text { Kerupuk } \\
\text { Kemplan } \\
\text { g }\end{array}$ & 4 & $\begin{array}{l}\text { Punggung } \\
\text { membungku } \\
\mathrm{k} \quad 36^{0} \\
\text { pergerakan } \\
\text { tangan } \\
\text { berulang, } \\
\text { dan kaki di } \\
\text { tekuk terlalu } \\
\text { dalam }\end{array}$ & $\begin{array}{l}\text { Punggung } \\
\text { membungkuk } \\
\text { menyebabkan } \\
\text { nyeri otot pada } \\
\text { leher , bahu, } \\
\text { punggung dan } \\
\text { pingggang dan } \\
\text { kaki yang terlalu } \\
\text { dalam di tekuk } \\
\text { dapat } \\
\text { menyebabkan } \\
\text { nyeri pada kaki }\end{array}$ & $\begin{array}{l}\text { Punggung } \\
\text { tidak terlalu } \\
\text { membungkuk } \\
\text { dan kaki tidak } \\
\text { terlalu di tekuk } \\
\text { kedalam }\end{array}$ & $\begin{array}{l}\text { Kursi dan meja } \\
\text { tempat duduk } \\
\text { dan tempat } \\
\text { pembentukan } \\
\text { kerupuk } \\
\text { kemplang } \\
\text { pekerja agak di } \\
\text { tingggikan }\end{array}$ \\
\hline
\end{tabular}


Dari analisis diatas dapat diketahui banyak postur-postur kerja yang memungkinkan pekerja tidak nyaman dengan adanya postur kerja yang tidak alamiah. Maka dari itu perlu adanya perubahan dari postur kerja dan alat bantunya. Rekomendasi yang dusulkan dari analisa di atas bahwa ada beberapa kegiatan atau postur yang memerlukan perancangan alat, baik berupa meja atau landasan, alat bantu dan juga tata letak dari fasilitas yang terdapat di stasiun kerja. Rekomendasi yang dilakukan dari usulanusulan mengenai rancangan alat bantu dan metode kerja yang baru, diharapkan pekerja dapat mengetahui alat bantu yang lebih baik dan nyaman ketika digunakan. Selain itu pekerja dapat mengetahui postur kerja yang benar dalam melakukan aktivitasnya.

\section{Kesimpulan}

Kesimpulan yang didapat dari penelitian ini adalah postur kerja yang aman dapat direkomendasikan menurut metode RULA pada kegiatan pengambilan sagu cair agar punggung tidak terlalu membungkuk di perlukan adanya penambahan perancangan alat bantu landasan seperti meja, kegiatan pembentukan adonan kerupuk kemplang agar postur kerja pundak tidak terlalu terangkat keatas maka pengambilan adonan tidak terlalu berlebihan, pada kegiatan pemanggangan kerupuk kemplang agar punggung tidak terlalu membungkuk dan kaki tidak terlalu di tekuk kedalam diperlukan adanya penambahan perancangan kursi dan meja tempat duduk dan tempat pembentukan kerupuk kemplang pekerja agak di tingggikan. Penelitian ini disarankan untuk dapat dilanjutkan oleh peneliti lainnya khususnya dalam hal mendesain meja, kursi dan peralatan yang ergonomis terutama pada bagian pembuatan adonan sagu cair dengan penambahan fasilitas kerja seperti meja, hal ini dapat membantu operator untuk memudahkan pengambilan bahan baku sehingga tidak terlalu membungkuk. Pada bagian pembentukan adonan perlu adanya perbaikan meja kerja agar tidak terlalu rendah, sehingga operator tidak terlalu tinggi mengangkat bahu pada saat pengulenan adonan kerupuk kemplang, dan pada bagian pemanggangan perlu adanya perbaikan fasilitas kerja seperti kursi dan meja agar dibuat sedikit lebih tinggi pada kursi supaya kaki operator tidak terlalu menekuk kedalam dan meja untuk penggeprekan kerupuk kemplang juga dibuat sedikit lebih tinggi untuk memudahkan pekerjaan dan dapat sesuai dengan kursinya.

\section{Daftar Pustaka}

Astuti, R.D. (2007). Analisa Pengaruh Aktivitas Kerja Dan Beban Angkat Terhadap Kelelahan Muskuloskeletal. Gema Teknik Majalah Ilmiah Teknik 10.2: 27-32.

Hamdy, M.I. (2020). Analisa Postur Kerja Manual Material Handling (MMH) Pada Karyawan Bagian Pembuatan Block Menggunakan Metode Rapid Upper Limb Assessment (RULA) (Studi Kasus: PT Asia Forestama Raya). Jurnal Teknik Industri: Jurnal Hasil Penelitian dan Karya Ilmiah dalam Bidang Teknik Industri 5.1: 62-65.

Hanif, Ahmad (2020). Hubungan Antara Umur 
Dan Kebiasaan Merokok Dengan Keluhan Musculoskeletal Disorders (MSDS) Pada Pekerja Angkat Angkut UD Maju Makmur Kota Surabaya. Medical Technology and Public Health Journal 4.1: 7-15.

Hartono, A. F. D., Soewardi, H. (2019).

Analisis Faktor-Faktor Resiko

Penyebab Musculoskeletal

Disorders Dan Stres Kerja (Studi

Kasus Di PLN PLTGU Cilegon).

Jurnal Ilmiah Teknik Industri (Jurnal

Keilmuan Teknik dan Manajemen Industri).

Hastuti, R.P. (2009). Hubungan Antara Sikap

Kerja Duduk Dengan Gejala Cumulative Trauma Disorders Pada Tenaga Kerja Bagian Penjahitan Konveksi Aneka Gunungpati Semarang. Doctoral Dissertation. Universitas Negeri Semarang.

Indrawan, Dimas (2019). Perbaikan Postur Kerja Pada Proses Penghalusan Giboult Joint Untuk Meminimalisasi Resiko Cidera (Studi Kasus Pada PT. Aneka Adhilogam Karya, Klaten). Tugas Akhir. Universitas Pembangunan Nasional Veteran Yogyakarta.

Kasjono, H.S., Yamtana., Pandini, D.I. (2017).

Faktor Risiko Manual Handling dengan Keluhan Nyeri Punggung Bawah Pembuat Batu Bata. Jurnal

Kesehatan 8.2: 202-211.

Katherine Macella Silvanus, et al. (2017).

Analisis Resiko Postural Stress Pada

Pekerja di UD. XYZ Dengan Metode Rapid Upper Limb Assessment. Jurnal Rekayasa Sistem Industri 6.2: 149-154.

Luopajarvi, T. (1990). Ergonomic Analysis Of Workplace And Postural Load. Ergonomics: The Physiotherapist In The Workplace. Edinburgh, London, Melbourne and New York: 51-78.

Mahardika, Tanjung., \& Pujotomo.D. (2014). Perancangan Fasitilas Kerja Untuk Mengurangi Keluhan Musculoskeletal Disorders (MSDS) Dengan Metode
Rappid Entire Body Assesment Pada Pekerja Pembuatan Paving Dan Batako Pada UKM Usaha Baru. J@ti Undip: Jurnal Teknik Industri 9.2: 109-116.

Pratiwi, Indah (2012). Evaluasi Postur Kerja di Industri Tahu-Kartasura. Seminar Nasional Ergonomi.

Pratiwi, Indah., Aprillia, Linda., \& Zulfa, Cita. (2014). Evaluasi Postur Kerja Pengrajin Gerabah Menggunakan RULA dan REBA. IENACO (Industrial Engineering National Conference).

Puspita, A. D. (2019). Analisis Aktivitas Kerja Dengan Pendekatan Ergonomi Assessment RULA Dan REBA. Teknik Industri, 22(01).

Ramdhani, D. (2018). Analisis Postur Kerja Pengrajin Handycraft Menggunakan Nordic Body Map Dan Metode Rapid Upper Limb Assessment (RULA). Doctoral Dissertation. Fakultas Teknik.

Rinawati, Seviana. (2016). Analisis Risiko Postur Kerja Pada Pekerja Di Bagian Pemilahan dan Penimbangan Linen Kotor Rs. X. Journal of Industrial Hygiene and Occupational Health 1.1: 39-52.

Septyadi, Evin. (2018). Analisa Postur Kerja Yang Terjadi Pada Aktivitas Dalam Proses Penjahitan Di Konveksi Pakaian Dengan Metode Rula (Studi Kasus UKM Safira Collection, Yogyakarta.

Setiawan, A. (2017). Rancangan Kursi Operator Cold Shear Dengan Pendekatan Ergonomi

Antrophometri Dan Analytical Hirarchy Process Di PT Ispat Panca Putera. Doctoral Dissertation. Universitas Muhammadiyah Gresik.

Siswanto, (2019). Analisis Postur Kerja Operator Sablon Karung Dengan Metod Rula Dan Wera (Studi Kasus: UD. Eka Jaya).Dissertation. Universitas Muhammadiyah Gresik. 
Surya, R.Z. (2017). Pemetaan Potensi Muskuloskletal Disorders (MSDS) Pada Aktivitas Manual Material Handling (MMH) Kelapa Sawit. Jiems (Journal of Industrial Engineering And Management Systems) 10.1.

Tambuwun, J. H., Malonda, N. S., \& Kawatu, P. A. (2020). Hubungan Antara Usia Dan Masa Kerja Dengan Keluhan Muskulo-Skeletal Pada Pekerja Mebel Di Desa Leilem Dua Kecamatan Sonder. Medical Scope Journal, 1(2).

Tarwaka, 2014. Keselamatan Dan Kesehatan Kerja Manajemen Dan Implementasi K3 Di Tempat Kerja. Solo: Harapan Press.

Triyanto, Budi. (2012). Analisis Postur Kerja Menggunakan Metode Rula Dan Perancangan Ulang Stasiun Kerja Finishing Batik (Studi Kasus Pada Ukm Pembuatan Batik Printing Di Desa Pilang, Masaran, Sragen). Dissertation. Universitas Muhammadiyah Surakarta.

Umyati, Ani., \& Mariawati, A.S. (2018). Pemetaan Keluhan Cidera Otot Rangka Akibat Kerja Pada Kelompok Wanita Pengolah Ikan Di Daerah Pesisir Kabupaten Pandeglang. Prosiding Semnastek 1.1 .

Yuliana, Yuliana., Yamtana., \& Achmad Husein. (2019). Penerapan Kursi Ergonomis Dan Peregangan Untuk Mengurangi Keluhan Nyeri Punggung Pada Pekerja Di Industri PT."X" Kebumen Jawa Tengah. Jurnal Teknologi Kesehatan (Journal of Health Technology) 15.1: 8-14. 